\title{
Metastatic Kaposi Sarcoma
}

National Cancer Institute

\section{Source}

National Cancer Institute. Metastatic Kaposi Sarcoma. NCI Thesaurus. Code C156475.

Kaposi sarcoma that has spread from its original site of growth to another anatomic site. 